\title{
Closure of perforator veins with glue. Early results.
}

\author{
I Bihari ${ }^{1}$, G $^{\text {Ayoub }}{ }^{1}, \mathbf{P}$ Bihari $^{1}$ \\ ${ }^{1}$ A and B Clinic Budapest, Hungary. 42-44, Nepszinhaz utca, Budapest, Hungary 1081. Tel: +36-30-9605-855
}

submitted: Nov 12, 2020, accepted: Dec 9, 2020, EPub Ahead of Print: Dec 18, 2020

Conflict of interest: None

DOI: 10.24019/jtavr.92 - Corresponding author:Dr. Imre Bihari, imre.bihari.dr@ gmail.com

(C) 2018 Fondazione Vasculab impresa sociale ONLUS. All rights reserved.

\begin{abstract}
AIM. With the introduction of endovenous varicose vein surgery, the closure of perforator veins has become easier to perform. There were several complications with classical perforator vein interruption surgery, which could be avoided with these new techniques. Perforator vein interruption is recommended mainly for the treatment of severe CVI but we performed our study on primary varicose vein cases. PATIENTS. 252 perforator veins were treated in CEAP C2-3-4-5 limbs. Glue was not used in open legs (C6) to avoid contamination of a permanently remaining foreign material. METHOD. Insufficient perforator veins were found with US examination. Direct puncture was performed and 0.1-0.5 ml (mean $0.28 \mathrm{ml}$ ) VenaBlock was given according to the diameter of the vein. This superglue-like material
\end{abstract}

\section{Introduction}

The treatment of perforator veins (PV) has a long history. Firstly classical surgical interruption was developed $^{1,2}$. This meant extended surgery with several long skin incisions, time-consuming preparations, heavy blood loss and longer operating time. There were frequent complications, such as infections and other wound healing problems. There was a significant development when G. Hauer introduced the endoscopic method (SEPS) ${ }^{3}$. This operation was recommended in crural ulcer and chronic venous insufficiency cases ${ }^{4}$. Ever since this technique was introduced, it has also been carried out in primary varicosity cases 5 . SEPS requires special training and equipment. Sclerotherapy and foam sclerotherapy are also available, but their results are not as convincing and are only used in less serious cases ${ }^{6,7,8,9}$.

In our recurrent varicose vein cases, PVs were found in $20.3 \%$ as main sources. Others also examined recurrent solidifies in 2-5 seconds, so injection must be performed quickly. RESULTS. In US check-ups $84.9 \%$ of perforator veins were closed. Although $15.1 \%$ remained open only in $10.3 \%$ of them was refluxive. We did not find any complications or side effects. CONCLUSIONS. We support the opinion of other colleagues that glue is suitable for occluding perforator veins. Its usage is easier than non-endovenous methods. It contributed to the elimination of varicose veins, but to judge its real value, a longer observational period is necessary. There were no signs of inflammatory or granulomatous complications in any case.

Keywords varicosity, perforator veins, cyanoacrylate ablation, complications, Turkish glue

cases, and in $75 \%$ found insufficient perforator veins ${ }^{10}$. We decided to close the insufficient ones during varicose vein surgery. It is known that the benefits of PV closure in primary varicose vein cases is not proven yet ${ }^{11}$.

In recent decades, different endovenous techniques have been worked out. Almost all of them are suitable for perforator vein closure. This technique is less demanding for the patient and surgeon, and does not require different equipment than the varicose vein surgery itself ${ }^{10,11}$.

There is an opinion that PVs contribute significantly to the drainage of varicose veins, and so saving them is recommended in some cases in spite of the fact that they are insufficient ${ }^{12}$. In our material, there were cases where some years later these saved perforator veins became sources of recurrent varicosities. For this reason, in our study every 
insufficient perforator vein was treated, and glue was used for this purpose.

Our aims were: to judge the suitability of glue for PV closure, the early results of this procedure on varicosity, and the consequences of its widespread usage in terms of side effects and complications.

\section{Patients}

From 1 March 2019 until 30 June 2020, 174 patients (101 women, 73 men) were treated. The youngest patient was 20 and the oldest 85 (mean 52.4). In 187 legs, 252 PVs were treated (1.35 PV/leg) (Table I). Known and treated ailments, such as hypertension, hypo- and hyperthyreosis, coronaria sclerosis, diabetes mellitus and anticoagulation, did not influence the indication. Most of our cases were primary varicosities: only 5 post-thrombotic and 2 congenital malformation limbs were treated. In 35 limbs, recurrent varicosities were treated (18.7\%). CEAP classification of our cases are shown in Table II. In open leg cases, no glue surgery was performed.

\section{Methods}

The insufficiency of PVs was detected with $\mathrm{US}^{13}$. In 178 limbs, PV closure was performed together with laser surgery of saphenous stems. In 9 limbs, glue surgery was carried out for the saphenous stems and PVs. VenaBlock (Invamed, Turkey) was used in every case, which is $\mathrm{N}$ butyl-cyanocrylate. The main characteristic of this product is that it sets as a superglue in 2-5 seconds. We had to elaborate our PV closure technique accordingly.

Firstly, the glue is apirated into an insulin syringe. Secondly, the perforator vein is punctured with a $18 \mathrm{G}$ needle. Its intraluminal position is proved by the aspiration of blood. The tip of the needle is positioned at the fascia level. Knowing that paravenously injected glue material evokes a more serious immune response than that given intraveously, glue was administered exclusively when the tip of the needle was in the lumen ${ }^{14}$. The amount of glue injected is adjusted to the diameter of the PV: so many times $0.1 \mathrm{ml}$ is given as the diameter is in $\mathrm{mm}$. The smallest amount was 0.1 and the biggest 0.5 , mean $0.28 \mathrm{ml}$. Different needles can have about $0,05-0.1 \mathrm{ml}$ capacity.

Glue is injected as the syringe is joined to the needle, to avoid the glue setting within the syringe. After injection, the vessel is compressed for half a minute with the head of the US. Because of the sound shadow of the glue, there is no possibility to orient oneself about the position of the glue or patency of the deep veins. Usually the distance between PVs is enough to perform several PV closures without the disturbance of shadows.
Because PV closures are performed together with laser surgery of the saphenous stems, we used propofol anaesthesia during this combination of venous interventions. Local anaesthesia alone was only given in those cases where glue surgery was used for the treatment of saphenous stems ( 9 cases). After this combined surgery, compression treatment was employed for 2-4 weeks.

\section{Results}

Our cases were checked after 1, 3 and 8 weeks. Inspection and palpation: after some days and later, there was no visible sign of the intervention. The hyperaemia, inflammation, and tenderness which are present in 10-20 percent of GSV glue surgery cases was not found in any limbs at the site of the perforator vein interventions ${ }^{15}$. There was no oedema, stagnation or new varicose vein or pain along the limb either.

Complaints: There was no resting pain or pain during movement. At the first check-up there was a minimal tenderness at the PV closure site in $23 \%$.

US findings: In the early post-operative period, the injected glue is clearly visible. It is easy to differentiate it from the vessel wall and a sound shadow is also present. The occlusion rate of PVs is in Table III. Judgement of patency of deep veins was not possible in each case because of the mentioned sound shadow, but in most cases their patency was clearly seen (Fig 1, 2). Later check-ups (after 2 months) showed less discernable glue and shadow in general.

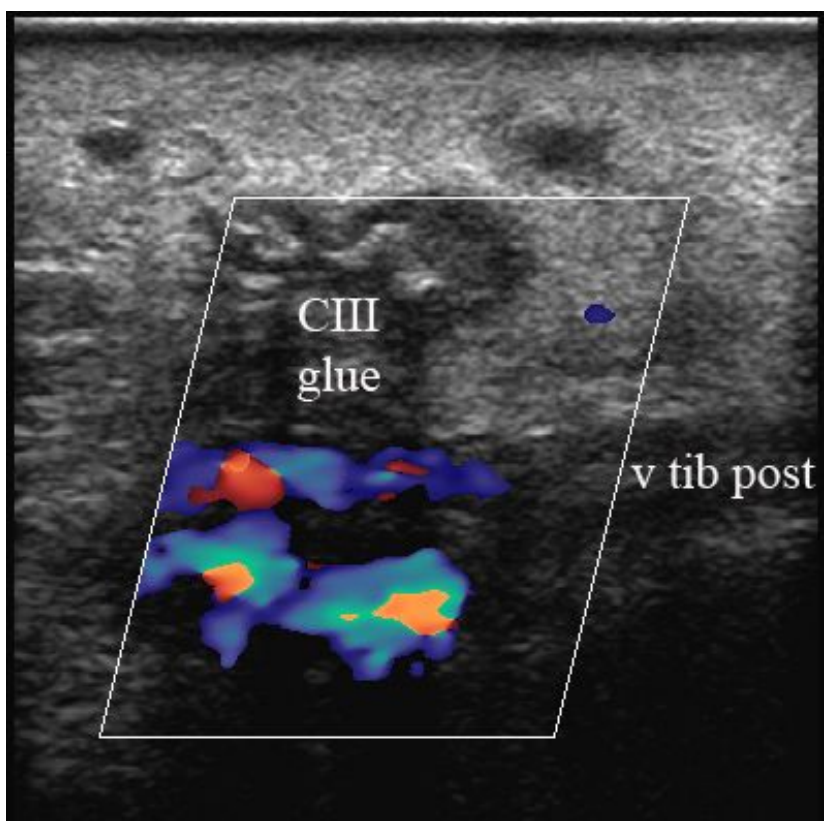

Fig 1 - US picture of the Cockett III PV which is closed with glue. The tibial posterior vein is patent. 


\begin{tabular}{|lc|}
\hline & No \\
Perforator vein & 5 \\
Cockett I & 8 \\
Cockett II & 119 \\
Cockett III & 26 \\
Sherman & 9 \\
Boyd & 22 \\
Gastrocnemius & 2 \\
Soleus & 35 \\
Anterior tibial & 6 \\
Peroneal & 8 \\
Popliteal fossa & 6 \\
Dodd & 1 \\
Lateral thigh & 1 \\
Posterior thigh & 1 \\
Gluteal & 3 \\
Perineal & \\
& 252 \\
Total & \\
Table I - Glue treated perforator veins & \\
\hline
\end{tabular}

\begin{tabular}{|c|c|c|}
\hline CEAP clinical & \multicolumn{2}{|c|}{ No } \\
\hline $\mathrm{C}-1$ & \multicolumn{2}{|c|}{0} \\
\hline $\mathrm{C}-2$ & \multicolumn{2}{|c|}{128} \\
\hline $\mathrm{C}-3$ & \multicolumn{2}{|c|}{12} \\
\hline $\mathrm{C}-4$ & \multicolumn{2}{|c|}{23} \\
\hline $\mathrm{C}-5$ & \multicolumn{2}{|c|}{24} \\
\hline C-6 & \multicolumn{2}{|c|}{0} \\
\hline Total & \multicolumn{2}{|c|}{187} \\
\hline \multicolumn{3}{|c|}{ Table II - CEAP clinical class of treated limbs } \\
\hline US result of PVs & No & $\%$ \\
\hline Closed & 214 & 84,9 \\
\hline Open without reflux & 12 & 4,8 \\
\hline Open with reflux & 26 & 10,3 \\
\hline Total & 252 & 100,0 \\
\hline
\end{tabular}

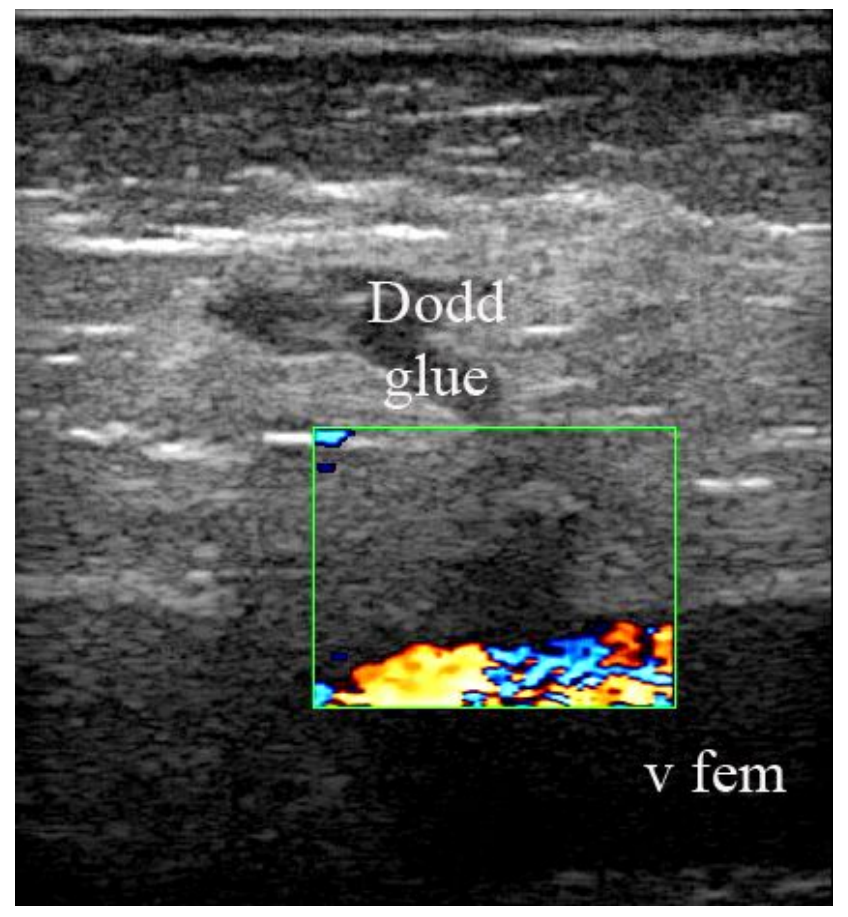

Fig 2 - US picture of the closed Dodd PV. Good flow in the femoral vein.

\section{Discussion}

There are different opinions regarding the indication of interventions on perforator veins. It is usually accepted that in crural ulcer and severe CVI cases, closure of insufficient PVs is recommended ${ }^{10,11}$. Our experience in our country is that, in those serious CVI cases where insufficient perforator surgery is recommended, the interruption is not ultimately performed, mainly because of the fear of complications. The situation is very different in complication-free primary varicose vein cases: there is no clear evidence that the recurrency rate is lower if insufficient PVs are interrupted ${ }^{11}$. An exception is if the $\mathrm{PV}$ is the only source of varicosity. Other insufficient PVs can serve as part of the private circulation of the limb, and have a role in redirecting the blood into the deep veins. This means that, after the removal of sources of varicosity and/ or varicose stems and branches, these insufficient PVs can normalise. This happened in 12 PVs $(4.8 \%)$ of our cases. There is a question as to why this did not happen similarly in the further $26(10.3 \%)$ non-responding cases.

Our observation is that, if a radical varicose vein surgery or tight compression is performed, there is no problem with the circulation of the limb, because the main 
venous drainage is in the deep system. The superficial venous network is connected to the deep vessels by 100 - 150 PVs, which suggests that eliminating one of them will not cause any drainage complications in the superficial system $^{10,16}$. In our short follow-up period, there was no congestion in any treated region or development of varicosity. A longer observation period is necessary to judge the real value of PV closures.

The introduction of endovenous methods in PV surgery makes the closure much easier than in the classical surgical intervention. We have experience in PV closure with laser. In this case a relatively high amount of energy is necessary to occlude PVs, which can cause damage in the nerves that can be found in the same channel as PVs.This complication did not occur in our glue cases.

There has been little published about PV glue closure so far, mainly presentations at different conferences ${ }^{17-20}$. The only published paper is about some experience with Vena Seal $^{17}$. They all support this technique.

The next important question is about the risks of glue usage. It is well known that in 10-20 \% of GSV treatment cases, there is an inflammatory immune response in the thigh along the course of the vein. This response was not found in any of our PV treatment cases. The other possible

\section{References}

1) Linton RR, Atlas of vascular surgery. Philadelphia: WB Saunders Company; 1973. p. 146-57.

2) DePalma RG. Linton's operation and modifications of the open techniques. In: Gloviczki P, Bergan JJ, editors. Atlas of endoscopic perforator vein surgery. London: Springer; 1998. 107-13.

3) Hauer G: The endoscopic subfascial division of the perforating veins. VASA 14:59-61. (1985)

4) Wittens CHA. Comparison of open Linton operation with subfascial endoscopic perforator vein surgery. In: Gloviczki P, Bergan JJ, editors. Atlas of endoscopic perforator vein surgery. London: Springer; 1998. 107-13.

5) Jugenheimer $M$, Junginger $T$ : Endoscopic subfascial sectioning of incompetent perforating veins in treatment of primary varicosis. World J Surg, 16(5):971-5. (1992)

6) Goor W. Sclerotherapy of incompetent perforating veins. In: May R, Partsch H, J. Staubesand J, editors. Perforating veins. München: Urban and Schwarzenberg, 1981, p. 239-246.

7) Barrett JM. Ultrasound-guided foam sclerotherapy of large varicose veins. In: Bergan JJ, Cheng VL, Foam sclerotherapy. London: Roy Soc Med Press, 2008, p. 117-28.

8) Rabe E, Breu FX, Cavezzi A, Coleridge Smith P, Frullini A, Gillet JL, Guex JJ, Hamel Desnos C et al. European guidelines for sclerotherapy in chronic venous disorders. Phlebology. 2014; Jul;29(6):338-54. doi: 10.1177/0268355513483280.

9) Gianesini S, Obi A, Onida S, et al. Global guidelines trends and controversies in lower limb venous and lymphatic disease: complication is the development of granulomas ${ }^{11,14}$. This response was not seen either.

Regarding post-operative patency of deep veins, we did not see any clinical sign of occlusion. With the use of VenaBlock, it is riskier to experience the glue setting within the syringe than to experience some overflow of the material into the deep veins, but it cannot be excluded. To prevent thrombotic occlusion, as part of the laser surgery in our practice, LMWH prophylaxis is routinely used and for this reason it was employed in these cases. Due to the sound shadow of the glue, US check-up of deep veins was not reliable in every case.

In conclusion, we can say that in this short-term study glue was found effective in PV occlusion. This is a less demanding technique than a classical surgical intervention, and avoids the complications of heat ablation techniques. No serious complication was found during our observation period. Regarding the necessity of these insufficient perforator veins, it seems that their closure did not cause any disturbance in the venous circulation. Its benefits regarding the recurrency rate will be seen in a longer follow-up. It is not yet known why there is no inflammatory or granulomatous response in this location. Glue was found to be effective and less risky than others, so it seems worth collecting experience with this method.

Narrative literature revision and experts' opinions following the vWINter international meeting. Phlebology, 34(IS):4-66. 2019

10) Wittens C, Davies AH, Baekgaard N et al. Editor's Choice Management of Chronic Venous Disease Clinical Practice Guidelines of the European Society for Vascular Surgery (ESVS), EJVES, 2015;49(6):678-737

11) A Nicolaides, S Kakkos , N Baekgaard, A Comerota, M De Maeseneer, B Eklof, A Giannoukas, M Lugli, O Maleti, A Mansilha, KA. Myers, O Nelzen, H Partsch, M Perrin et al. Management of chronic venous disorders of the lower limbs. Int Angiol 2020;39:175-240.

12) Franceschi C, Zamboni P. Principles of venous hemodynamics. New York, Nova Biomedical Books; 2009.

13) De Maesseneer M, Pichot O, Cavezzi A et al. Duplex ultrasound examination of the veins of the lower limbs after treatment of varicose veins. UIP consensus document. ESJVS 2011; 42(1):89-102.

14) Parsi K, Kang M, Yang A, et al. Granuloma formation following cyanoacrylate glue injection in peripheral veins and arteriovenous malformation. Phlebology, 2019; DOI: $\underline{10.1177 / 0268355519856756}$

15) Parsi K, Roberts S, Kang M. Cyanoacrylate closure for peripheral veins: Consensus document of the Australasian College of Phlebology. Phlebology, 2020 Apr;35(3):153-175.

16) Gloviczki P, Mozes G. Development and anatomy of the venous system. In: Gloviczki P, editor, Handbook of venous disorders. London, Hodder Arnold; 2009. p. 12-24. 
I Bihari, G Ayoub, P Bihari - Closure of perforator veins with glue. Early results.

17) Toonder MI, Lam LY, Lawson J, Wittens CH. Cyanoacrylate adhesive perforator embolization of incompetent perforating veins of the leg, a feasibility study. Phlebology 2014; DOI: 10.1177/0268355514529696. Epub 2014 May 19.

18) Bozkurt K. Treatment of incompetent perforators with glue. World Congress of Phlebology; 2018 Febr 4-8; Melbourne, Australia
19) Matar L. Direct injection of cyanoacrylate adhesive into perforators. World Congress of Phlebology, 2018 Febr 4-8; Melbourne, Australia

20) Paraskevas P. Month trial of gluing perforators. World Congress of Phlebology; 2018 Febr 4-8; Melbourne, Australia 
